\title{
Analysis of urban dew intensity variable regular pattern
}

\author{
Xinyue $\mathrm{Zhu}^{1, \mathrm{a}}$, Yingying $\mathrm{Xu}^{1, \mathrm{~b}}$
}

${ }^{1}$ Key Laboratory of Songliao Aquatic Environment Jilin Jianzhu University, Changchun 130118;

aemail: zhuxinyue3366@163.com, bemail:xuyingying.1019@aliyun.com

Keywords: Dew condensation; Poplar stick; Dew intensity; Vertical direction

\begin{abstract}
In order to explore the urban ecosystem dew spatial variation, in 2015 the plant growth period (from the end of the Apr. to the middle of the Nov.) in the suburb of Changchun City by poplar stick and bitumen sheet as the dew on the ground and the ground monitor, the dew of field observation. The results showed that the dew intensity reached its maximum in August, autumn dew intensity is the largest, while the spring dew intensity is the smallest. In the vertical direction of the various layers of dew intensity overall change trend of the same, the intensity of the bottom dew is higher than that of the plant upper canopy, the plant canopy on the ground is weakest.
\end{abstract}

\section{Introduction}

Water is the most widely distributed and most important part of the earth, it is an indispensable substance in the life of the body, in a variety of forms exist in the natural world. Due to the different underlying surface. In the desert[1], tropical rainforest [2], urban[3] and wetland[4] ecosystem, water circulation differences, regional differences in climate and human activities has significant influence on the water cycle rules [5]. Therefore, in recent years dew as an essential component of the water cycle has been widely concerned.

Study on the dew resource has been an important subject in meteorology and agriculture and ecology and other related disciplines and areas of common concern, has the vital significance to the ecological and environmental protection and agricultural production development utilization of dew resources in arid and semi arid region development is a very good development prospects of scientific work. Foreign scholars began to study and scientific exposition of the formation of dew in early nineteenth Century[6]. In 1957 Monteith[7] proposed the definition of dew, dew refers to water vapor condensation in the atmosphere radiation to a matrix product. Further study on urban dew after 1950s.

The domestic research work started late, the research on the area and the limitation of the dew, limited the people to explore the ecological effect of dew. Fang et al[8] observation experiment on the condensation water of sandy soil in arid desert area. Fan [9] on with typical inland arid climate in the north part of Tianshan mountain plain condensate analysis, discusses the environmental effect of condensation of water vapor.

At present, there are many researches on the dew in the plain, oasis and the area of grassland, arid area, but little research on the strength of urban dew. Dew is one of the objective existence of water sources, in addition to the quality of the importance of the reflected, the dew intensity also has a certain climate and ecological effects. Therefore, this study is to enrich the dew data, to better understand the importance of dew, dew condensation on the outskirts of Changchun city observation. The study of dew condensation in urban ecosystem is a great significance.

\section{Methods and materials}

In Jilin Jianzhu University, Changchun City, Jilin Province, Jingyue Development Zone set up observation points, from 2015 in April to November to carry out daily monitoring. Jilin Jianzhu University is located in the southeast of Changchun City, Changchun city in the northern hemisphere mid latitude north temperate zone, located in the hinterland of the Northeast China Plain, is a north temperate continental monsoon climate zone. Changchun City, the annual average 
temperature of $4.8{ }^{\circ} \mathrm{C}$, the highest temperature $39.5{ }^{\circ} \mathrm{C}$, the lowest temperature $-39.8{ }^{\circ} \mathrm{C}$, the average annual precipitation $522 \sim 615 \mathrm{~mm}$, summer precipitation accounted for more than $60 \%$ of the annual precipitation; the hottest month (7 months) the average temperature of 23 degrees.

Dew monitor according to the difference of underlying surface species diversity, collector of different materials, different surface structures, moisture absorption is different, therefore collector on the calculation of dew amount has a certain influence. This paper mainly discusses the green area on the outskirts of urban plants and surface dew condensation strength, therefore the selection of poplar stick[10] and bitumen sheets as a collector, both of them can reflect the different underlying surface dew condensation and regular shape, easy to calculate the surface area and scattered dew is not easy, easy to carry. The observation frame is made of stainless steel, and there are three height of observation and erection: the base of the plant $(5 \mathrm{~cm}$ up the ground); the canopy of the plant(25cm up the ground); the top of the plant $(50 \mathrm{~cm}$ up the ground), each layer is provided with a monitoring arm.

2015 plant growth period (from the end of the Apr. to the middle of the Nov.) in the green area to set up the observation frame, in a clear night to observe the green area. Experimental within 30 min after sunset will be accurate weighing monitoring green area monitor were placed in frames with different height to the observational arm observations, each highly placed three monitor; and before sunrise within 30 minutes will take the monitor under, the monitor into the sealing good clean plastic box, immediately transferred to the laboratory weighing (balance accurate to $0.0001 \mathrm{~g}$ ). If the monitor has weight gain that day there was a layer of dew condensation events, denoted as a dew days, increase the weight is dew condensation of water amount, or that the day without the occurrence of dew condensation events, denoted as no dew days.

In order to express the dew condensation ability, with dew intensity $(I)$ to define land (including plants and soil) someday dew amount, can be calculated in accordance with the following formula:

$$
I=\frac{10 \times\left(W_{r}-W_{s}\right)}{S}
$$

Formula (1) in the $I$ for the dew intensity $(\mathrm{mm}) ; W_{r}$ for the collector to collect dew weight (g); $W_{s}$ for the collector's initial weight (g); $S$ for the collector's specific surface area $\left(\mathrm{cm}^{2}\right)$; 10 for the conversion factor.

\section{Temporal variation of dew intensity}

Dew day number $(D)$ is the number of days of dew events at night. There are obvious differences between the four seasons in Changchun, summer rainfall is more frequent, if the nocturnal rainfall is recorded as no dew days; low temperature in winter, if the highest outdoor temperature to zero Celsius degrees below (cream), dew data collection. The dew of Changchun area generally appeared in late April to early November, mainly concentrated in the period from May to October. Such as the figure 1 shown in July and October dew days most, besides dew monitoring 4 and 11 months, August dew days are the least; August maximum number of days of rainfall, comparison can be seen that rainfall is the main factor affecting the number of dew. 


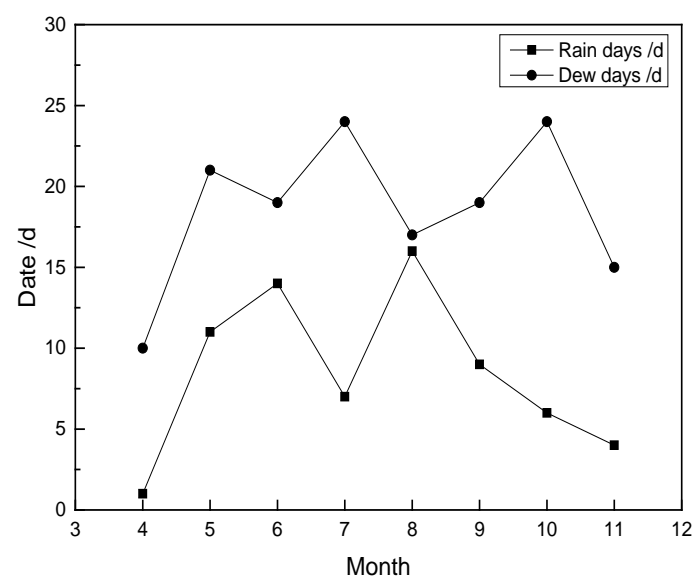

Fig.1. Dew days and rain days in suburb of Changchun

The beginning of spring, the beginning of summer, the beginning of autumn, the beginning of winter is divided into four seasons of Changchun. In spring and winter, the temperature is low in the two season, the dew day is less, and the data collection is not complete, so the data of summer and autumn in the two season can reflect the dew condensation in the suburb of Changchun city.

Non parametric test and Q-Q probability map test in the software of SPSS 19.0. The suburb of Changchun City to plant dew intensity showed a normal distribution, surface dew intensity refuses to accept from a normal distribution, so on the seasonal plant dew intensity were single factor variance analysis (ANOVA) in LSD test. Results show that the intensity of dew in spring, summer and autumn, winter season between the two groups there were significant difference $(P<0.05)$; spring and winter dew intensity does not exist significant difference $(P>0.05)$; summer and autumn dew intensity does not exist significant difference $(P>0.05)$; the autumn dew intensity are maximum, and spring minimum mean. It is known that summer and autumn dew condensation ability basically flat, in the four seasons condensation ability is higher than spring and winter.

\section{Spatial variation of dew intensity}

As the figure 2 shown, monitoring of plant dew is divided into three layers, namely the bottom (about $5 \mathrm{~cm}$ up the ground), plant canopy (about $25 \mathrm{~cm}$ up the ground) and plant upper canopy (about $50 \mathrm{~cm}$ up the ground). Due to different height of the water vapor source and other factors, resulting in different heights of dew strength. In the early growth stages in April and may plant, canopy dew intensity values, bottom and canopy dew intensity were not significantly different $(P>0.05)$, due to the June to October each layer of dew intensity is positively normal distribution, available arithmetic average intensity, on behalf of the size. From June to September plants were more flourishing, and the bottom dew intensity was the highest, the last of upper canopy, the canopy was the weakest. Plants began to wither in October, and the changes in the intensity of the dew, but almost the same. 




Fig.2. Vertical variation of dew intensity in Changchun

\section{Conclusion}

In the analysis of the dew intensity data of each month, the dew intensity reached the peak in August, and the intensity of plant dew was higher than that of the ground. There was no significant difference in the dew intensity between summer and autumn $(P>0.05)$, but was significantly higher than that in spring and winter $(P<0.05)$. The autumn dew intensity is the largest, while the spring dew intensity is the smallest. In the vertical direction, the total variation of dew intensity was the same, the intensity of the bottom dew is higher than that of the plant upper canopy, the plant canopy on the ground is weakest.

\section{Acknowledgement}

In this paper, the research was sponsored by the Nature Science Foundation of Henan Province (Project No. 201112400450401) and Youth Fund Project of Luoyang Institute of Science and Technology (Project No. 2010QZ16).

\section{References}

[1] Abraham Zangvil. Six years of dew observations in the Negev Desert,Israel[J]. Journal of Arid Environments, 1996, 32: 361-371.

[2] Victor L.Barradas, M. Guadalupe Glez-Medellin. Dew and its effect on two heliophile understorey species of a tropical dry deciduous forest in Mexico[J]. International Journal of Biometeorology, 1999, 43(1): 1-7.

[3] Richards K. Urban and rural dew fall, surface moisture, and humidity measurements for Vancouver, Canada[J]. Boundary-Layer Meteorology, 2005, 114: 143-163.

[4] Xu Yingying, Yan Baoxing, Guo Yuedong. Measurement and Analysis of Formation Conditions of Dew in marsh[J]. Wetland Science, 2009, 7(2): 156-161.

[5] Zhang Qiang, Zhao Yingdong, Zhang Cunjie, et al. Issues about hydrological cycle and water resource in arid region of Northwest China[J]. Arid Meteorology, 2008, 6(2): 2-8.

[6] W.H.Wells, An essay on dew, and several appearances connected with it[J]. Taylor and Hessey, London, 1814.

[7] Monteith, J. L Dew[J]. Quarterly Journal of the Royal Meteorological Society, 1957, 83: 322-341.

[8] Fang Jing, Ding Yongjian. An experimental observation of the relationship between sandy soil condensation water and micrometeorological factors in the arid desert region[J]. Journal of Desert 
Research, 2015, 35(5): 1200-1205.

[9] Fan Gaogong. Experimental research on the formation of condensation water and analyzing its eco-environmental impact[J]. Journal of Xi'An engineering university, 2002, 12(4):63-66.

[10] Yan Baixing, Xu Yingying, Wang Lixia. Dew condensation rules in farmland ecosystem in Sanjiang plain[J]. Acta Ecologica Sinica, 2010, 30(20): 5577-5584. 